\title{
High alcohol consumption in Germany: results of the German National Health Interview and Examination Survey 1998
}

\author{
Martina Burger* and Gert BM Mensink \\ Robert Koch-Institute, Department of Epidemiology and Health Reporting, Seestraße 10, D-13353 Berlin, Germany
}

Submitted 6 October 2003: Accepted 27 April 2004

\begin{abstract}
Objective: To analyse the alcohol consumption behaviour of the German adult population, with a focus on the characteristics of persons drinking more than the tolerable upper alcohol intake level (TUAL) of $10-12 \mathrm{~g} \mathrm{day}^{-1}$ for healthy adult women and $20-24 \mathrm{~g} \mathrm{day}^{-1}$ for healthy adult men.

Design and setting: For the German National Health Interview and Examination Survey 1998, a representative sample of free-living adults was drawn. A total of 7124 participants were interviewed comprehensively about their sociodemographic background, lifestyle and eating habits including alcohol consumption.

Subjects: A sub-sample of 4030 women and men, 18-79 years old, who were involved in the integrated German Nutrition Survey.

Results: About $16 \%$ of women and $31 \%$ of men had mean alcohol consumption above the TUAL. Among other factors, the inclination to exceed the TUAL was related to middle-age, high socio-economic status, smoking and use of soft drugs. Among both women and men, a high proportion of persons drinking above the TUAL was observed among those consuming low amounts of soft drinks, fruit, poultry, milk products, bread and cake/biscuits. Women preferred to drink wine, whereas men preferred to drink beer.

Conclusions: Many Germans have an alcohol consumption level above the TUAL and thus are supposed to be at increased risk for alcohol-associated diseases.
\end{abstract}

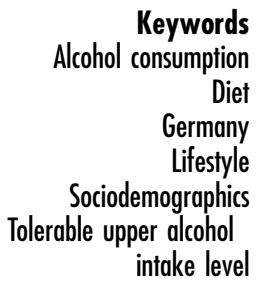

Several decades of research have shown that alcohol consumption may lead to hazardous health and social consequences. Still, it took a long time to achieve knowledge about the alcohol intake level up to which adverse health effects become unlikely for the majority of the population. Only recently, a systematic review focused on obtaining such a tolerable upper alcohol intake level (TUAL) and established the limits of $10-12 \mathrm{~g}$ alcohol day ${ }^{-1}$ for healthy adult women and $20-24 \mathrm{~g}$ alcohol day ${ }^{-1}$ for healthy adult men ${ }^{1}$. It is assumed that people drinking above the TUAL have an increased risk of, for instance, liver cirrhosis and cancer of the respiratorydigestive tract.

The purpose of this study was to gain an overview of alcohol drinking in Germany with a focus on the TUAL. The analyses are based on cross-sectional data from the German National Health Interview and Examination Survey (GNHIES) 1998 and the integrated German Nutrition Survey (GeNuS) 1998, and give a first insight into the multitude of sociodemographic and other healthrelevant characteristics that are associated with high alcohol consumption.

\section{Methods}

\section{Study population}

In total, 7124 non-institutionalised women and men between 18 and 79 years of age participated in the representative GNHIES 1998. The study population was drawn from population registries stratified for age, gender, community size and federal state. The overall participation rate was $61.4 \%$. Participants underwent a physical examination including measurement of height and weight, and completed a questionnaire on sociodemographic, lifestyle and other health-related issues. Regular checking ensured internal and external quality. The survey has been described in more detail elsewhere ${ }^{2,3}$.

\section{Dietary assessment}

A randomly selected sub-sample of 2267 women and 1763 men participated in the GeNuS $1998^{4}$. Participants were interviewed about their dietary behaviour by trained nutritionists using the validated dietary assessment software DISHES 98 (Dietary Interview Software for Health Examination Studies) $)^{5}$. The DISHES interview is a 
modified dietary history interview, which asks for the usual intake of foods and drinks during the preceding four weeks. The assessment of alcohol consumption during the interview comprised questions on drinking frequency, drinking amounts per typical drinking occasion and beverage type. For each participant, information on food and beverage consumption was converted to an average nutrient intake per day using the German Food Code and Nutrition Data Base (Bundeslebensmittelschlüssel), version II. $3^{6}$.

\section{Data analyses}

Analyses are based on the 2267 female and 1763 male participants of the GeNuS 1998. They were classified in age bands of 18-24, 25-34, 35-44, 45-54, 55-64 and 65-79 years. Information on education level, occupation and household income resulted in a socio-economic status (SES) index with the categories of low, middle and high ${ }^{7}$. According to community size, population groups of $<5000,5000$ to $<100000$ and $\geq 100000$ inhabitants were formed. Smoking habits were categorised as never, current and former smoking. Sports activity was classified as no engagement in sports (sedentary persons), sports activity of $<2 \mathrm{~h}_{\text {week }}{ }^{-1}$ (moderately active persons) and sports activity of $\geq 2 \mathrm{~h} \mathrm{week}^{-1}$ (active persons), on a regular basis. Body mass index (BMI) was calculated by dividing weight (in kilograms) by the square of height (in metres). BMI of 20 to $<25 \mathrm{~kg} \mathrm{~m}^{-2}$ was defined as normal weight, BMI of 25 to $<30 \mathrm{~kg} \mathrm{~m}^{-2}$ as overweight and BMI of $\geq 30 \mathrm{~kg} \mathrm{~m}^{-2}$ as obese. Food intake data were summarised in specific food groups.

Persons reporting no alcoholic beverage intake were defined as non-drinkers. Persons with a consumption of $>10 \mathrm{~g}$ alcohol day $^{-1}$ for women and $>20 \mathrm{~g}$ alcohol day $^{-1}$ for men were considered to drink above the TUAL and to have high alcohol consumption. Specific information on consumption of beer, wine and spirits was used to define a person as preferential beer drinker, wine drinker or spirit drinker, if the respective beverage added up to more than half of the individual's total alcohol consumption. Alcohol as a percentage of total energy intake was calculated as $\left[\left(\mathrm{g}\right.\right.$ alcohol day $\left.{ }^{-1} \times 6.9 \mathrm{kcal} \mathrm{g}^{-1}\right) / \mathrm{kcal}$ total energy $] \times 100$. Further, food density variables were defined by dividing food intake in $\mathrm{g} \mathrm{day}^{-1}$ by energy intake in $\mathrm{kcal} \mathrm{day}^{-1}$ and, subsequently, quintiles of consumption for specified food groups were formed. Basal metabolic rate (BMR) was estimated using the Schofield formula, and low-energy reporters were defined as those with an energy intake below $1.27 \times \mathrm{BMR}^{8}$. Chi-square tests of proportions were performed for descriptive statistics. All tests were two-tailed, with a significance criterion of $P<0.05$. SAS statistical software (release 8.2; SAS Institute Inc., Cary, NC, USA) was used for statistical analyses, and all analyses were weighted to improve the representative status of the German non-institutionalised general population in 1998 .

\section{Results}

\section{Prevalence of high alcobol consumption}

In Germany, $15.4 \%$ of women drink more than the TUAL of $10 \mathrm{~g}$ alcohol day ${ }^{-1}$. About $5 \%$ of women even drink more than $200 \%$ of the TUAL. The proportion of men with alcohol consumption higher than the TUAL of $20 \mathrm{~g}$ alcohol $\mathrm{day}^{-1}$ is $30.8 \%$. The proportion of men drinking more than $200 \%$ of the TUAL is $10.6 \%$. Overall, $84.6 \%$ of women and $94.5 \%$ of men in Germany consume alcoholic beverages. Among alcohol drinkers, the prevalence of high alcohol consumption is $18.5 \%$ among women and $32.7 \%$ among men.

\section{Sociodemographic characteristics of high alcobol consumption}

The proportion of women drinking above the TUAL is highest among middle-aged women, the peak value being $22.3 \%$ among women $45-54$ years old (cf. 25-34 years: $13.7 \%, P=0.0028$ and $65-79$ years: $10.4 \%, P<0.0001$ ). The proportion of men drinking above the TUAL shows a similar dependence on age as the one observed for women. Nevertheless, the proportions within all age bands are $12-19 \%$ higher among men (Table 1). The proportion of women with high alcohol consumption increases significantly with higher SES. It is $8.7 \%$ in the lowest, $13.7 \%$ in the middle and $30.1 \%$ in the highest SES category. Among men, the inclination to drink above the TUAL is only significantly different for men of high (35.3\%) and middle SES $(28.6 \%, P=0.0065)$. As for geographical differences, the proportion of men drinking above the TUAL is significantly higher among those living in former East Germany (35.3\%) as compared with West Germany (29.7\%, $P=0.0304)$. We observe a significantly higher proportion of high alcohol consumption among women 
living in cities with 100000 or more inhabitants (19.6\%) compared with communities with fewer than 5000 inhabitants $(11.8 \%, P=0.0095)$ or with 5000-100000 inhabitants $(14.7 \%, P=0.0008)$.

\section{Psychoactive substances}

The proportion of women drinking above the TUAL is significantly lower among never smokers (12.1\%) than among current smokers $(18.5 \%, P=0.0003)$ and former smokers $(23.4 \%, P<0.0001)$. Among male never smokers, the proportion of men drinking above the TUAL is also lower (24.7\%) compared with current smokers and former smokers (36.7\%, $P<0.0001$ and $31.7 \%$, $P=0.0051$, respectively). High alcohol consumption is also associated with the use of marijuana, hashish and cannabis. The proportion of women drinking above the TUAL is $31.8 \%$ among consumers of soft drugs and $15 \%$ among non-consumers $(P<0.0001)$. Among men, the respective proportions are $44.5 \%$ and $29.6 \%(P<0.0001)$. A similar association is observed for high alcohol consumption and ecstasy; however, the number of ecstasy consumers was rather small.

\section{Otber lifestyle babits and BMI}

An alcohol consumption level above the TUAL is significantly more prevalent among moderately active $(18 \%, P=0.0018)$ and active women $(18.9 \%, P=0.0047)$ than among sedentary women (12.6\%). Contrary to women, among men the inclination to drink above the TUAL is equally distributed among different levels of sports activity. With respect to energy intake, alcohol is $1.9 \%$ (standard deviation (SD): 2.8; median: 0.8\%, interquartile range (IQR): $0.1-2.4 \%$ ) of total energy intake among women in general and 7.0\% (SD: 4.2\%; median: 5.8\%, IQR: $4.1-8.5 \%$ ) of total energy intake among women drinking above the TUAL. Alcohol intake as a percentage of energy is higher among men than among women (mean: $4.6 \%$, SD: 5.2\%; median: $3.1 \%$, IQR: $0.9-6.7 \%$ ) and is $10.2 \%$ (SD: 5.2 ; median: 8.8\%, IQR: 6.7-12.4\%) among men with high alcohol consumption. The proportion of women reporting to exceed the TUAL is significantly lower among those with a higher BMI; i.e. $20.6 \%$ among normal-weight, $14.4 \%$ among overweight and $8.9 \%$ among obese women. Contrary to women, a significantly higher inclination to drink above the TUAL is observed among overweight (33.1\%, $P=0.0036)$ and obese $(33.3 \%, P=0.0196)$ men than among men with normal weight (26.2\%).

Differences in the proportions of high alcohol consumers by quintile of food intake are presented in Table 2 for women and in Table 3 for men. Women in the lowest consumption quintile of soft drinks, fruit, cabbage, poultry, milk products and bread, as well as cake and biscuits, have a significantly higher inclination to drink above the TUAL compared with women in the highest consumption quintiles. Similar tendencies were observed among men. However, men with a relatively low consumption of juice, water, non-alcoholic beverages, cereals, pasta and sweets, as well as a relatively high consumption of potatoes, vegetables and fish, also tend to have high alcohol consumption.

Table 2 Percentage of women drinking more than $10 \mathrm{~g}$ alcohol day ${ }^{-1}$ by quintile of food intake $(n=2072)$

\begin{tabular}{lcccccc}
\hline Food group & First quintile & $\begin{array}{l}\text { Second } \\
\text { quintile }\end{array}$ & Third quintile & $\begin{array}{c}\text { Fourth } \\
\text { quintile }\end{array}$ & Fifth quintile & $P$-value \\
\hline Beverages & & & & & & \\
$\quad$ Soft drinks & 22.3 & 14.4 & 15.4 & 11.2 & 11.9 & $<0.0001$ \\
$\quad$ Fruit and vegetable juice & 17.2 & 13.0 & 13.5 & 18.7 & 15.5 & NS \\
$\quad$ Mineral and tap water & 11.5 & 15.5 & 16.0 & 20.1 & 14.9 & NS \\
Coffee & 15.4 & 16.3 & 15.8 & 14.8 & 15.9 & NS \\
$\quad$ Non-alcoholic beverages & 13.8 & 16.4 & 15.0 & 18.5 & 14.1 & NS \\
Foods & 15.6 & 18.0 & 17.3 & 14.9 & 12.1 & 0.0044 \\
Fruit & 15.4 & 14.3 & 15.3 & 15.7 & 17.4 & NS \\
Potatoes & 14.7 & 13.7 & 17.6 & 14.2 & 17.6 & NS \\
Leaf salad and herbs & 20.1 & 14.5 & 15.4 & 17.5 & 10.9 & 0.0003 \\
Cabbage & 12.6 & 15.7 & 14.5 & 17.7 & 17.7 & NS \\
Other vegetables & 15.9 & 16.6 & 13.9 & 14.0 & 17.9 & NS \\
Red meat & 15.7 & 16.3 & 13.5 & 18.1 & 14.6 & 0.0009 \\
Poultry & 15.2 & 16.0 & 14.8 & 15.0 & 17.3 & NS \\
Sausage & 12.2 & 15.4 & 15.9 & 15.8 & 19.0 & NS \\
Fish & 11.9 & 13.8 & 17.6 & 16.4 & 19.1 & NS \\
Eggs & 21.3 & 15.8 & 14.5 & 14.0 & 12.4 & 0.0029 \\
Milk products & 16.5 & 18.7 & 12.0 & 16.0 & 14.9 & $<0.0001$ \\
Bread & 15.4 & 13.9 & 14.4 & 16.3 & 18.2 & NS \\
Cereals & 14.9 & 16.3 & 14.1 & 13.7 & 19.3 & NS \\
Pasta & 20.5 & 15.6 & 14.5 & 12.1 & 15.2 & 0.0208 \\
Cake and biscuits & 20.6 & 16.1 & 12.8 & 12.4 & 16.5 & NS \\
Sweets & & & & & & \\
\hline
\end{tabular}

NS - not significant.

* Significant difference $(P<0.05)$ between the proportion of women drinking $>10 \mathrm{~g}$ alcohol day ${ }^{-1}$ in the first and fifth quintile of density of the specified food (chi-square test). 
Table 3 Percentage of men drinking more than $20 \mathrm{~g}_{\text {alcohol day }}{ }^{-1}$ by quintile of food intake $(n=1958)$

\begin{tabular}{|c|c|c|c|c|c|c|}
\hline Food group & First quintile & $\begin{array}{l}\text { Second } \\
\text { quintile }\end{array}$ & Third quintile & $\begin{array}{l}\text { Fourth } \\
\text { quintile }\end{array}$ & Fifth quintile & $P$-value \\
\hline \multicolumn{7}{|l|}{ Beverages } \\
\hline Soft drinks & 38.5 & 29.9 & 32.6 & 24.2 & 25.5 & $<0.0001$ \\
\hline Fruit and vegetable juice & 37.4 & 32.8 & 31.5 & 27.1 & 25.4 & $<0.0001$ \\
\hline Mineral and tap water & 37.8 & 34.6 & 27.6 & 29.9 & 25.4 & 0.0001 \\
\hline Coffee & 28.2 & 27.2 & 31.0 & 34.3 & 33.2 & NS \\
\hline Non-alcoholic beverages & 40.3 & 32.6 & 32.1 & 25.5 & 24.9 & 0.0006 \\
\hline \multicolumn{7}{|l|}{ Foods } \\
\hline Fruit & 32.4 & 35.8 & 30.6 & 26.3 & 29.1 & 0.0002 \\
\hline Potatoes & 28.9 & 26.8 & 30.3 & 34.3 & 33.9 & 0.0388 \\
\hline Leaf salad and herbs & 31.7 & 28.0 & 29.5 & 29.3 & 35.3 & NS \\
\hline Cabbage & 30.4 & 29.1 & 29.3 & 26.0 & 39.2 & NS \\
\hline Other vegetables & 27.5 & 32.6 & 30.7 & 33.0 & 30.3 & 0.0018 \\
\hline Red meat & 25.8 & 27.0 & 30.2 & 36.0 & 35.6 & NS \\
\hline Poultry & 31.7 & 31.6 & 33.6 & 28.7 & 28.9 & 0.0044 \\
\hline Sausage & 26.9 & 29.0 & 33.4 & 32.3 & 33.4 & NS \\
\hline Fish & 27.0 & 28.0 & 34.0 & 32.4 & 33.2 & 0.0309 \\
\hline Eggs & 26.0 & 29.6 & 31.2 & 33.6 & 33.9 & NS \\
\hline Milk products & 40.0 & 31.7 & 30.6 & 28.4 & 24.3 & $<0.0001$ \\
\hline Bread & 32.8 & 31.0 & 30.2 & 31.6 & 28.3 & $<0.0001$ \\
\hline Cereals & 38.2 & 32.7 & 32.5 & 25.4 & 27.3 & 0.0006 \\
\hline Pasta & 34.5 & 28.5 & 33.6 & 29.2 & 28.9 & 0.0035 \\
\hline Cake and biscuits & 39.6 & 30.1 & 31.9 & 25.3 & 27.1 & 0.0028 \\
\hline Sweets & 38.1 & 31.7 & 33.2 & 27.6 & 24.6 & $<0.0001$ \\
\hline
\end{tabular}

NS - not significant

* Significant difference $(P<0.05)$ between the proportion of men drinking $>20 \mathrm{~g}$ alcohol day ${ }^{-1}$ in the first and fifth quintile of density of the specified food (chi-square test).

\section{Drinking pattern}

The percentage of alcohol from wine, beer and spirits is $61.2 \%, 26.5 \%$ and $12.4 \%$ among women and $27.9 \%, 65.4 \%$ and $6.8 \%$ among men. Spirit drinkers are less prevalent among women drinking above the TUAL (4.1\%) as compared with those drinking less $(11 \%, P=0.0001)$. In contrast, female wine drinkers are more prevalent among those with high (68.7\%) rather than low alcohol consumption $(61.6 \%, P=0.0192)$. Among men, the proportion of both spirit drinkers and wine drinkers is lower among those drinking above the TUAL. On the other hand, the proportion of beer drinkers is significantly higher among men with high alcohol consumption (76.6\%) than among those drinking less $(65.7 \%, P<0.0001)$.

\section{Discussion}

According to population data for the year $1998^{9}, 16 \%$ of women and $31 \%$ of men with drinking level above the TUAL are equivalent to approximately 5.1 and 9.6 million persons, respectively. Against this background, a considerable number of German adults face an increased alcohol-associated health risk. However, these figures may be understated, as persons who voluntarily participate in health surveys may be more health-conscious than the general population and, moreover, institutionalised persons and derelicts were not included.

An alcohol intake above the TUAL was most prevalent among middle-aged persons. However, the relatively high proportion of young adults with an alcohol intake above the TUAL, that is $11.3 \%$ of women and $23.9 \%$ of men
18-24 years old, is particularly alarming, since any alcohol consumption may be harmful to their health ${ }^{1}$. Some studies have observed a linear association between alcohol consumption and total mortality among young adults, mainly caused by accidents and violence ${ }^{10-12}$.

Since alcohol is the second most energy-dense macronutrient $\left(6.9 \mathrm{kcalg}^{-1}\right)$ and alcoholic drinks may also not be as satiating as solid foods with similar energy content, moderate alcohol consumption is supposed to promote overweight ${ }^{13}$. This is in line with the observed association among men ${ }^{13,14}$. Among women, however, high alcohol consumption is more common among normal-weight than among both overweight and obese women. This association remained after excluding lowenergy reporters. A lower BMI with increasing alcohol consumption has been observed by others ${ }^{15-17}$. Several explanations for this have been proposed. For example, the metabolism of alcohol may involve the activation of energy-wasting metabolic pathways and suppress the oxidation of other substrates ${ }^{14,18,19}$. As women are more weight-conscious than are men, women in particular may compensate for alcohol consumption by a reduction of food intake. However, some studies could not confirm this $^{16,20}$. Factors other than the above-mentioned alcohol substitution may influence alcohol-related energy balance, including drinking pattern, dietary composition and BMI $^{13,15,17,21}$. Furthermore, smoking habits may affect the alcohol-related energy balance of women and men in different ways $^{14}$. In addition, results of the present study suggest that gender differences in sports activity may also play a role in the effect of alcohol consumption on BMI. 
As people compose their diet in the form of foods, not nutrients, we analysed the relationship between high alcohol consumption and food choice. Results of previous studies were inconsistent ${ }^{13,16,22}$, although several studies showed alcohol consumption to be positively associated with meat intake and inversely associated with the intake of fruit and milk products. Differences in culture, but also in study methods including dietary assessment instruments, may contribute to the inconsistencies. Moreover, other studies focused on differences in food choice in different alcohol consumption groups rather than on the proportion of persons with high alcohol consumption in regard to low or high consumption of specified foods, as done in this study.

People drinking above the TUAL may generally lead a less health-conscious life, which in fact was shown for smoking habits and drug use. The relationship between high alcohol consumption and sports activity and dietary habits, however, was less obvious. Our results suggest that the dietary pattern of women with high alcohol consumption is less favourable than the one of others (except for the low consumption of cake and biscuits). However, we could not observe a similar dietary pattern among men. The definition of high alcohol consumption made in this study may differ from the understanding of high alcohol consumption in society. For this reason, even people who are conscious of their health do not automatically drink less than the TUAL. This may also explain the higher alcohol consumption among persons of high SES, who are better educated and generally considered to be more health-conscious and to drink in socially accepted contexts.

We classified persons as predominant beer, wine or spirit drinkers and observed differences in the prevalence of high alcohol consumption with respect to beverage preference. Previous studies give no explicit evidence that wine consumption is more beneficial (or harmful) than the consumption of other alcoholic beverages ${ }^{23}$. However, some studies suggest that the preference for a specific beverage type is associated with a lifestyle pattern that reflects typical health-related behaviour ${ }^{24-26}$.

As the distributions of alcohol consumption and energy intake are highly skewed, neither mean nor median values reflect the true distributions. Proportions of the prevalence of high alcohol consumption are more illustrative and, consequently, are presented in this study. Although some of the observed associations with alcohol consumption may be affected by uncontrolled confounding, for instance by age, major characteristics associated with high alcohol consumption could be identified. In a next step, multiple analyses are required to confirm the presented findings and in addition to reveal interactions.

Underreporting is a well-known problem in the assessment of alcohol consumption. In the DISHES interview, consumption of any alcoholic beverage during and between meals was assessed. This method may have positively influenced the participants' memory. Moreover, by including questions on alcohol in the overall dietary assessment, the tendency to report socially accepted alcohol use might have been minimised. The relative validity of DISHES 98 was previously determined by comparing it with a 3-day weighed protocol, with a 24-hour dietary recall and, in an additional study, with a food-frequency questionnaire ${ }^{5,27}$. The alcohol consumption reported in the DISHES interview was also compared with the results of a food-frequency questionnaire included in GNHIES 1998 (not shown). Assessment by the dietary recall method showed higher alcohol consumption, although the correlation of alcohol consumption was relatively high between both methods. In addition, the proportion of women and men grouped in the same or adjacent quintile of intake observed by both methods was relatively high.

\section{Conclusions}

The apparently low average alcohol consumption of $5 \mathrm{~g}$ (median: $2 \mathrm{~g}$ ) per day among women and $17 \mathrm{~g}$ (median: $11 \mathrm{~g}$ ) per day among men in Germany has to be considered with caution, as the proportion of persons with high alcohol consumption is relatively high. It is assumed that persons drinking regularly above the TUAL are exposed to an increased risk of ill health and premature death. For this reason, it becomes necessary to further characterise these persons in regard to health promotion projects. Such information is also important for deeper insight into the mechanisms of alcohol-associated outcomes, as these characteristics may be confounders and/or effect modifiers for the relationship of alcohol consumption to specific health effects ${ }^{22,28}$. In summary, this study provides a first understanding of potential determinants of alcohol consumption among German adults.

\section{References}

1 Burger M, Brönstrup A, Pietrzik K. Alkobolkonsum und Krankheiten [Alcobol Consumption and Disease]. BadenBaden: Bundesministerium für Gesundheit, 2000.

2 Thefeld W, Stolzenberg H, Bellach B-M. Bundes-Gesundheitssurvey: Response, Zusammensetzung der Teilnehmer und Non-Responder-Analyse [German National Health Interview and Examination Survey: response, composition of participants, and analysis of non-respondents]. Gesundbeitswesen 1999; 61: S57-61.

3 Bellach B-M, Knopf H, Thefeld W. Der Bundes-Gesundheitssurvey 1997/1998 [The German National Health Examination Survey 1997/1998]. Gesundheitswesen 1998; 60: $559-68$.

4 Mensink GBM, Hermann-Kunz E, Thamm M. Der Ernährungssurvey [The German Nutrition Survey]. Gesundheitswesen 1998; 60: 83-6.

5 Mensink GBM, Haftenberger M, Thamm M. Validity of DISHES 98, a computerised dietary history interview: energy and macronutrient intake. European Journal of Clinical Nutrition 2001; 55: 1-9. 
6 Dehne LI, Klemm C, Henseler G, Hermann-Kunz E. The German Food Code and Nutrient Data Base (BLS II.2) European Journal of Epidemiology 1999; 15: 355-9.

7 Winkler J, Stolzenberg H. Der Sozialschichtindex im BundesGesundheitssurvey [Social status scaling in the German National Health Interview and Examination Survey] Gesundheitswesen 1999; 61: S178-83.

8 Goldberg GR, Black AE, Jebb SA, Cole TJ, Murgatroyd PR, Coward WA, et al. Critical evaluation of energy intake data using fundamental principles of energy physiology: 1 . Derivation of cut-off limits to identify under-recording. European Journal of Clinical Nutrition 1991; 45: 569-81.

9 Statistisches Bundesamt. Statistisches Jahrbuch 2002 für die Bundesrepublik Deutschland [Statistical Year book 2002 for the Federal Republic of Germany]. Wiesbaden: Statistisches Bundesamt (Federal Statistical Office), 2002.

10 Rehm J, Sempos CT. Alcohol consumption and all-cause mortality. Addiction 1995; 90: 471-80.

11 Klatsky AL, Armstrong MA, Friedman GD. Alcohol and mortality. Annals of Internal Medicine 1992; 117: 646-54.

12 Andreasson S, Allebeck P, Romelsjo A. Alcohol and mortality among young men: longitudinal study of Swedish conscripts. British Medical Journal 1988; 296: 1021-5.

13 Maennistoe S, Pietinen P, Haukka J, Ovaskainen ML, Albanes D, Virtamo J. Reported alcohol intake, diet and body mass index in male smokers. European Journal of Clinical Nutrition 1996; 50: 239-45.

14 Hellerstedt WL, Jeffery RW, Murray DM. The association between alcohol intake and adiposity in the general population. American Journal of Epidemiology 1990; 132: 594-611.

15 Colditz GA, Giovannucci E, Rimm EB, Stampfer MJ, Rosner $\mathrm{B}$, Speizer FE, et al. Alcohol intake in relation to diet and obesity in women and men. American Journal of Clinical Nutrition 1991; 54: 49-55.

16 Toniolo P, Riboli E, Cappa AP. A community study of alcohol consumption and dietary habits in middle-aged Italian women. International Journal of Epidemiology 1991; 20 663-70.

17 Gruchow HW, Sobocinski KA, Barboriak JJ, Scheller JG. Alcohol consumption, nutrient intake and relative body weight among US adults. American Journal of Clinical Nutrition 1985; 42: 289-95.

18 Siler SQ, Neese RA, Hellerstein MK. De novo lipogenesis, lipid kinetics, and whole-body lipid balances in humans after acute alcohol consumption. American Journal of Clinical Nutrition 1999; 70: 928-36.

19 Shelmet JJ, Reichard GA, Skutches CL, Hoeldtke RD, Owen OE, Boden G. Ethanol causes acute inhibition of carbohydrate, fat, and protein oxidation and insulin resistance. Journal of Clinical Investigation 1988; 81: 1137-45.

20 Veenstra J, Schenkel JA, van Erp-Baart AM, Brants HA, Hulshof KF, Kistemaker C, et al. Alcohol consumption in relation to food intake and smoking habits in the Dutch National Food Consumption Survey. European Journal of Clinical Nutrition 1993; 47: 482-9.

21 Clevidence BA, Taylor P, Campbell WS, Judd JT. Lean and heavy women may not use energy from alcohol with equal efficiency. Journal of Nutrition 1995; 125: 2536-40.

22 Kesse E, Clavel-Chapelon F, Slimani N, van Liere M. Group E3N. Do eating habits differ according to alcohol consumption? Results of a study of the French cohort of the European Prospective Investigation into Cancer and Nutrition (E3NEPIC). American Journal of Clinical Nutrition 2001; 74 322-7.

23 Goldberg IJ, Mosca L, Piano MR, Fisher EA. Wine and your heart: a science advisory for healthcare professionals from The Nutrition Committee, Council on Epidemiology and Prevention, and Council on Cardiovascular Nursing of the American Heart Association. Circulation 2001; 103: 472-5.

24 Rimm E. Alcohol and cardiovascular disease. Current Atherosclerosis Reports 2000; 2: 529-35.

25 Burke V, Puddey IB, Beilin LJ. Mortality associated with wines, beers, and spirits. British Medical Journal 1995; 311: 1166.

26 Klatsky AL, Armstrong MA, Kipp H. Correlates of alcoholic beverage preference: traits of persons who choose wine, liquor or beer. British Journal of Addiction 1990; 85: 1279-89.

27 Koppes LLJ, Twisk JWR, Snel J, Kemper HCG. Concurrent validity of alcohol consumption measurement in a 'healthy' population; quantity-frequency questionnaire v. dietary history interview. British Journal of Nutrition 2002; 88: 427-34.

28 Klatsky AL. Diet, alcohol, and health: a story of connections, confounders, and cofactors. American Journal of Clinical Nutrition 2001; 74: 279-80. 